\title{
Acceptance and Utilisation of Sulphadoxine-Pyrimethamine and Insecticide-Treated Nets among Pregnant Women in Oyo State, Nigeria
}

\author{
Aderonke A. Adeola ${ }^{1}$ and Eugenia A. Okwilagwe ${ }^{2}$ \\ ${ }^{1}$ Federal Training Centre for Teachers of Health Sciences, University College Hospital, Ibadan 02234, Nigeria \\ ${ }^{2}$ Institute of Education, University of Ibadan, Ibadan, Nigeria \\ Correspondence should be addressed to Eugenia A. Okwilagwe; geniaokwilagwe2004@yahoo.com
}

Received 24 September 2015; Revised 23 November 2015; Accepted 1 December 2015

Academic Editor: Neena Valecha

Copyright ( 92015 A. A. Adeola and E. A. Okwilagwe. This is an open access article distributed under the Creative Commons Attribution License, which permits unrestricted use, distribution, and reproduction in any medium, provided the original work is properly cited.

\begin{abstract}
The study is an investigation of the acceptance and utilisation of Sulphadoxine-Pyrimethamine (Fansidar), the drug of choice for Intermittent Preventive Treatment in pregnancy, and Insecticide-Treated Nets among pregnant women who access different health facilities in Oyo State, Nigeria. Pregnant women (582) attending government primary healthcare antenatal clinics and 50 attending faith clinics purposively selected responded to structured instruments that were analysed using percentages, $t$-test correlation, and multiple regression. Acceptance and utilisation of RBM tools were higher in government clinics than faith clinics and in rural areas. Pregnant women in government clinics, $60.8 \%$ and $66.8 \%$, and faith clinics, $18 \%$ and $38.0 \%$, utilised Roll Back Malaria tools, significant at $t_{(630)}=5.81, p \leq 0.05$, and $t_{(630)}=3.99, p \leq 0.05$, respectively. Pregnant women in rural locations who accessed government clinics utilised Roll Back Malaria tools more than those in urban areas, $t_{(580)}=-641, p \leq 0.05$. Number of pregnancies, educational qualification of the pregnant women, and marital status significantly and consistently influenced acceptance and utilisation of these tools. To ensure that set targets are met, the utilization of RBM tools among the two categories of pregnant women can be improved by increasing the supply of the tools and ensuring that treatment is free.
\end{abstract}

\section{Introduction}

Malaria has been man's problem since the 14th century (the era of the black death in Europe), and now in the 21st century, its effect has again reached an alarming proportion. Malaria is the major and commonest cause of ill-health in Africa. It affects up to 500 million people worldwide annually [1]. Malaria remains a major threat to health and economic development of local communities and nations [2,3]. Almost half of the world's population is at risk of the disease [4-6]. Africa South of the Sahara records about $90 \%$ of the world's all malaria deaths [7] for two main reasons. The first is that infections are caused by Plasmodium falciparum (P. f.) (the most dangerous of the four human malaria parasites) and the second is because the mosquito Anopheles gambiae (the most effective malaria vector and also the most difficult to control) is most widespread in Africa [7].
Malaria infection during pregnancy is "a major public health problem in tropical and sub-tropical regions throughout the world" [8]. Children under 5 of years of age and pregnant women are recognised by the World Health Organization [9] as the vulnerable groups to malaria infection. The disease causes about 300-500 million clinical cases and 1.5 to 2.7 million deaths worldwide each year (WHO in [10]) even though there is a downward trend in these figures. The prevalence of malaria in Africa is high with an estimated average prevalence of P. f. of 63\% in West Africa and 39\% in Eastern and Southern Africa. Reports of outpatient visits due to malaria for some Africa countries such as Malawi, UR Tanzania, Uganda, and Zambia vary from 18\% in 1985 to $46 \%$ in 2000 while hospital admission due to malaria in these countries varies from $20 \%$ in 1985 to $60 \%$ in 2000 according to RBM [7]. Child mortality due to malaria seems to have been 
higher in Eastern/Southern Africa countries than in West African countries between 1990 and 1998. Malaria accounts for " $63 \%$ of the diseases reported in healthcare facilities across the six geopolitical zones of Nigeria," while it accounts for "11\% of maternal deaths" and its prevalence among pregnant women was put at " $47 \%$ malaria situation" in Nigeria in [4].

Insecticide-Treated Nets (ITNs) are known to be highly effective in the reduction of morbidity and mortality in malaria RBM [11]. In recent times, their usage in the African continent has been vigorously scaled up for coverage and in the introduction of Long-Lasting Insecticide Nets (LLINs). ITNs have been scaled up in many African countries among which are Tanzania, Zambia, Kenya, Mali, and Malawi (RBM [11]). In these countries, ITNs are usually distributed freely to parents of children and pregnant women (the vulnerable groups) while, in some countries, Nigeria inclusive, they are made available at retail shops and/or are supplied at subsidised prices or under the voucher scheme $[12,13]$.

$\mathrm{RBM}$ programme is put in place to assist endemic countries to conduct national needs assessments from which strategic plans could be developed. It also intended to serve as a forum to match country's plans with international donors. In view of the complications of malaria in pregnancy, especially in this period of drug resistant malaria parasites, Roll Back Malaria (RBM) programme was launched in 1998 with at least three new or refined tools to combat the disease [9]. The tools are "Artemisinin-Based Combination Therapies" (ACTs), "Insecticide-Treated Nets" (ITNs), and "Intermittent Preventive Treatment" (IPT) for pregnant women. Besides, other RBM measures used for malaria control are IRS, larval control, quick diagnosis, administration of ArtemisininBased Combination Therapies (ACTs) (freely given in some countries for all age groups), and adoption of chloroquine, mefloquine, and Sulphadoxine-Pyrimethamine (SP) (Fansidar) and primaquine. In spite of the efforts galvanised to combat malaria in Africa, there is still a high burden of malaria of $20 \%-40 \%$ with an average of $30 \%$ of all outpatient visits to the clinics in all African countries where malaria is endemic (RBM [7]). In many of these countries, the report indicated that between $20 \%$ and $50 \%$ of all hospital admissions are due to malaria. Reports (RBM [7]) indicate that less than $40 \%$ of malaria morbidity and mortality occur in formal health facilities which constitute a small fraction of the total burden but many of the reports do not include nongovernmental facilities like the faith clinics.

By 2005, it was expected that $60 \%$ of pregnant women in Nigeria would sleep under an ITN and 60\% of pregnant women would receive IPT using SulphadoxinePyrimethamine (SP) at least twice during ANC [4]. These targets were to gradually rise to a value between 75 and $80 \%$ by 2010 and coverage was sustained thereafter [12]. A national malaria situation survey conducted in 2000 reported by [4] indicated that preventive health behaviour in malaria in terms of net use among pregnant women in Nigeria seems to be generally low in all the six geopolitical zones. Also, [4] reported a generally poor usage of nets among all categories of people in Nigeria with only $20 \%$ of households owning nets, some of which are not necessarily ITNs, whereas [14] observed a higher coverage of the usage of nets in urban areas.

The need to further confirm current state of usage of RBM tools among this vulnerable group and the influence of location in this regard was crucial. In view of this, the present study had the impetus to investigate the acceptability and utilisation of RBM tools, their influencing factors, and the influence of location on the behaviour outcomes among pregnant women who access government and faith clinics in Oyo State, Nigeria, which seem to be usually sidelined by most health programmes initiated even when a sizeable number of pregnant women patronise them.

\section{Research Questions}

(1) What is the level of acceptance of Intermittent Preventive Treatment (IPT) of malaria in pregnancy and ITNs by pregnant women who attend different health facilities in Oyo State?

(2) Is there a difference in acceptance of IPT and ITNs by pregnant women in terms of the health facilities accessed and location?

(3) To what extent are IPT and ITNs utilised by pregnant women who access different health facilities in Oyo State?

(4) Is the utilisation of IPT and ITNs by pregnant women a function of the health facility accessed and location?

(5) Is there a relationship between acceptance and utilisation of IPT and ITNs by these pregnant women?

(6) What are the factors influencing (i) acceptance and (ii) utilisation of IPT and ITNs among pregnant women who access these health facilities in Oyo State?

\section{Materials and Methods}

3.1. Design. The study adopted the survey and causal comparative types of research as none of the variables were manipulated; they were studied as they occurred and inferences made on the basis of the findings obtained. The levels of acceptance and utilisation of Sulphadoxine-Pyrimethamine (Fansidar), the drug of choice for Intermittent Preventive Treatment (IPT) in pregnancy, and Insecticide-Treated Nets (ITNs) between government clinics and faith clinics or mission homes were compared.

3.2. Study Area and Sample. The study was conducted in Oyo State, Nigeria. Oyo State is located in the Southwest Geopolitical Zone of Nigeria and is one of the malaria endemic areas of the country. It consists of 33 local government areas with its capital city at Ibadan. The disease afflicts children under five and pregnant women-two of the most vulnerable groups-resulting in high morbidity and mortality in the state. For instance, data from [15] puts the trend of malaria prevalence in the state from a total of 358,780 cases in 2006 to 403,468 in 2009 . The study population consisted of all pregnant women in Oyo State, Nigeria, who were attending antenatal (ANC) clinics at both the Primary Healthcare 
Centres (PHC) and faith clinics, respectively, in 2009-2010 when the study was conducted. The 33 local government areas in the state were stratified into urban and rural composition and purposive sampling technique was employed to select three local government areas, respectively, from both urban and rural locations to take care of the location of the faith clinics/mission homes which were dominant in urban locations. All the PHC clinics and mission homes (faith clinics) in the selected local government areas were used for the study, while purposive sampling technique was used to select a total of 650 pregnant women but 582 who accessed government clinics and 50 who accessed faith clinics in these LGAs who had complete information on them formed the final sample.

3.3. Instrumentation. A structured questionnaire that was valid and reliable-Pregnant Women Acceptance and Utilisation Questionnaire (PWAUQ, $\alpha=0.81$ ) —used for data collection was administered once to the participants. PWAUQ consisted of background information about the pregnant women and their spouses' occupations and educational levels, locations, and number of pregnancies and their outcomes among others. The instruments on acceptance of RBM tools, utilisation of ITNs, and factors influencing acceptance and utilisation were closed-ended questions administered once to the participants. Data collection was carried out by the researchers with the assistance of fourteen trained assistants (six RBM programme managers in the six LGAs and eight others trained for the purpose of data collection). The researchers explained the purpose of the research work to all pregnant women that were present including the health workers at each PHC or faith clinic or mission home visited. Pregnant women in rural locations who had low educational qualification filled their questionnaire through the assistants who interpreted the contents to them in the local language Yoruba without influencing their responses.

3.4. Data Analysis. The data obtained were coded and analysed using the Statistical Package for the Social Sciences (SPSS) Version 20. Analyses of valid items were carried out and nonrespondents were excluded. Positive responses were coded with one (1) while negative responses were coded with zero (0). Percentages were computed for the responses relating to levels of acceptance and utilisation of RBM tools. Inferential statistics such as $t$-test and Analysis of Variance (ANOVA) were computed to determine significant levels of acceptance and utilisation of RBM tools between pregnant women who accessed government and faith-based health facilities and those in urban and rural locations. $p$ values of $\leq 0.05$ were considered as an acceptable level of significance. Pearson product moment correction was used to analyse the relationship between acceptance and utilisation of RBM tools. Multiple regressions were computed to establish the factors that influenced the acceptance and utilisation of the RBM tools.

\section{Results}

(1) What is the level of acceptance of Intermittent Preventive Treatment (IPT) of malaria in pregnancy and
ITNs by pregnant women attending different health facilities in Oyo State?

Pregnant women who accessed government clinics (49.8\%) tended to accept ITNs even though $72 \%$ of them claimed to "like sleeping under a mosquito net," while 52.2\% claimed they "accept IPT." A total of $28 \%$ and $30 \%$ of pregnant women who accessed faith clinics reported that they accepted these RBM tools, respectively, though $72 \%$ of them indicated they "like sleeping under a mosquito net" and 64\% "react to antimalarial drugs" (Table 1).

(2) Is there a difference in the acceptance of IPT and ITNs by pregnant women in terms of the health facility accessed and location?

There was a significant difference in acceptance of IPT and ITNs by pregnant women in the two health facilities in Table $2, t_{(630)}=3.51, p \leq 0.05$, and $t_{(630)}=4.15, p \leq 0.05$, respectively. Pregnant women in government clinics with $\mathrm{M}=$ $4.74, \mathrm{SD}=1.08$ and $\mathrm{M}=4.66, \mathrm{SD}=1.15$ seem to accept IPT and ITNs compared to their counterparts in faith clinics, Mean = $4.16, \mathrm{SD}=1.59 ; \mathrm{M}=3.96, \mathrm{SD}=0.93$. The effect sizes (Cohen's d) of 0.14 or $14 \%$ and 0.16 or $16 \%$, respectively, were obtained for the variance in acceptance in the two health facilities.

Significant influence of location was observed on the extent to which pregnant women in government health facility only accepted IPT (Table 3). Pregnant women in rural locations with Mean 4.92, SD $=1.00$ were better in the acceptance of IPT than those in the urban areas, Mean 4.55, $\mathrm{SD}=1.13, t_{(580)}=-4.12, p \leq 0.05$, with an effect size (Cohen's d) of 0.17 or $17 \%$. The influence of location on acceptance of ITNs was not significant, $t_{(580)}=-0.58, p \leq 0.05$. Faith clinics were not found in rural locations.

(3) To what extent are IPT and ITNs utilised by pregnant women attending different health facilities in Oyo State?

Pregnant women who accessed government clinics $(60.8 \%)$ utilised ITNs in spite of the claim that $62.9 \%$ reported "sleeping under an ITN before their current pregnancy" and $73.2 \%$ claimed "it is comfortable sleeping under an ITN." Among pregnant women who accessed faith clinics, $18 \%$ utilise ITNs even though $48 \%$ claimed they "find sleeping under an ITN comfortable." More women (66.8\%) in government clinics than their counterparts in faith clinics (38.0\%) used IPT to the expected two doses. As many as $79 \%$ of the pregnant women in government clinics and $62 \%$ in faith clinics indicated their willingness to use IPT in their subsequent pregnancies (Table 4).

(4) Is the utilisation of IPT and ITNs by pregnant women a function of the health facility accessed and location?

A significant difference in the utilisation of IPT and ITNs as presented in Table 5 was observed between these women, $t_{(630)}=5.81, p \leq 0.05$, and $t_{(630)}=3.99, p \leq 0.05$. Pregnant women in government clinics utilised IPT and ITNs more than those who accessed faith clinics. The effect sizes (Cohen's $d$ ) of 0.23 or $23 \%$ and 0.16 or $16 \%$, respectively, were 
TABLE 1: Acceptance of IPT and ITNs by pregnant women in Oyo State.

\begin{tabular}{|c|c|c|c|c|c|c|c|}
\hline \multirow[b]{2}{*}{$\mathrm{S} / \mathrm{N}$} & \multirow[b]{2}{*}{ Statement } & \multicolumn{3}{|c|}{ Government clinics $(N=582)$} & \multicolumn{3}{|c|}{ Faith clinic $(N=50)$} \\
\hline & & $\begin{array}{l}\text { Yes } \\
\%\end{array}$ & $\begin{array}{l}\text { No } \\
\%\end{array}$ & $\begin{array}{l}\text { No } \\
\text { response } \\
\%\end{array}$ & $\begin{array}{l}\text { Yes } \\
\%\end{array}$ & $\begin{array}{l}\text { No } \\
\%\end{array}$ & $\begin{array}{l}\text { No } \\
\text { response } \\
\%\end{array}$ \\
\hline 1 & $\begin{array}{l}\text { I like to sleep under mosquito } \\
\text { nets. }\end{array}$ & $\begin{array}{c}424 \\
(72.0)\end{array}$ & $\begin{array}{c}126 \\
(21.0)\end{array}$ & $\begin{array}{c}32 \\
(5.6)\end{array}$ & $\begin{array}{c}32 \\
(64.0)\end{array}$ & $\begin{array}{c}18 \\
(36.0)\end{array}$ & - \\
\hline 2 & $\begin{array}{l}\text { During this pregnancy I have } \\
\text { been sleeping under an ITN. }\end{array}$ & $\begin{array}{c}290 \\
(49.8)\end{array}$ & $\begin{array}{c}264 \\
(45.4)\end{array}$ & $\begin{array}{c}28 \\
(4.8)\end{array}$ & $\begin{array}{c}14 \\
(28.0)\end{array}$ & $\begin{array}{c}36 \\
(72.0)\end{array}$ & - \\
\hline 3 & I feel comfortable under the ITN. & $\begin{array}{c}315 \\
(54.1) \\
\end{array}$ & $\begin{array}{c}261 \\
(44.8) \\
\end{array}$ & $\begin{array}{c}6 \\
(1.0) \\
\end{array}$ & $\begin{array}{c}36 \\
(72.0) \\
\end{array}$ & $\begin{array}{c}8 \\
16.0 \\
\end{array}$ & $\begin{array}{c}6 \\
(12.0) \\
\end{array}$ \\
\hline 4 & $\begin{array}{l}\text { I have been coming to the clinic } \\
\text { to receive anti-malarial drug } \\
\text { (IPT) in this pregnancy. }\end{array}$ & $\begin{array}{c}304 \\
(52.2)\end{array}$ & $\begin{array}{c}232 \\
(39.9)\end{array}$ & $\begin{array}{c}46 \\
(7.9)\end{array}$ & $\begin{array}{c}15 \\
(30.0)\end{array}$ & $\begin{array}{c}27 \\
(54.0)\end{array}$ & $\begin{array}{c}8 \\
(16.0)\end{array}$ \\
\hline 5 & $\begin{array}{l}\text { I react to the anti-malarial drug } \\
\text { so I do not receive it. }\end{array}$ & $\begin{array}{c}402 \\
(69.1) \\
\end{array}$ & $\begin{array}{c}167 \\
(28.7) \\
\end{array}$ & $\begin{array}{c}13 \\
(2.2) \\
\end{array}$ & $\begin{array}{c}32 \\
(64.0) \\
\end{array}$ & $\begin{array}{c}11 \\
(22.0) \\
\end{array}$ & $\begin{array}{c}7 \\
(14.0) \\
\end{array}$ \\
\hline 6 & $\begin{array}{l}\text { I will accept IPT in subsequent } \\
\text { pregnancies. }\end{array}$ & $\begin{array}{c}390 \\
(67.0)\end{array}$ & $\begin{array}{l}170 \\
(29.2)\end{array}$ & $\begin{array}{c}22 \\
(3.8)\end{array}$ & $\begin{array}{c}31 \\
(62.0)\end{array}$ & $\begin{array}{c}14 \\
(28.0)\end{array}$ & $\begin{array}{c}5 \\
(10.0)\end{array}$ \\
\hline
\end{tabular}

TABLE 2: Summary of $t$-test analysis on acceptance of IPT and ITNs by pregnant women in terms of health facility accessed (government and faith clinics).

\begin{tabular}{lcccccc}
\hline Status & $N$ & Mean & SD & df. & $t$ & $d$ \\
\hline IPT in government clinics & 582 & 4.74 & 1.08 & \multirow{2}{*}{630} & \multirow{2}{*}{3.51} & 0.14 \\
IPT in faith clinics & 50 & 4.16 & 1.59 & & \multirow{2}{*}{$0.000^{*}$} \\
\hline ITNs in government clinics & 582 & 4.66 & 1.15 & \multirow{2}{*}{630} & 0.15 & 0.16 \\
ITNs in faith clinics & 50 & 3.96 & 0.93 & & $0.000^{*}$ \\
\hline
\end{tabular}

${ }^{*}$ Significant at $p \leq 0.05$.

TABLE 3: $t$-test analysis on acceptance of IPT and ITNs by pregnant women in government clinics by location.

\begin{tabular}{lllllllr}
\hline Group & Location & $N$ & Mean & SD & df. & $t$ & $d$ \\
\hline Acceptance of IPT by pregnant women & Urban & 278 & 4.55 & 1.13 & \multirow{2}{*}{580} & -4.12 & 0.17 \\
in government clinics & Rural & 304 & 4.92 & 1.00 & & $0.005^{*}$ \\
\hline Acceptance of ITNs by pregnant & Urban & 278 & 4.63 & 1.13 & \multirow{2}{*}{580} & -0.58 & \multirow{2}{*}{0.024} \\
women in government clinics & Rural & 304 & 4.68 & 1.17 & & $0.565^{\text {NS }}$ \\
\hline
\end{tabular}

${ }^{*}$ Significant at $p \leq 0.05, \mathrm{NS}=$ not significant at $p>0.05$.

obtained for the variance in the utilisation of IPT and ITNs, respectively.

A significant difference in the utilisation of IPT by the pregnant women who accessed government clinics by location, $t_{(580)}=-641, p \leq 0.05$, was observed with an effect size of 0.26 or $26 \%$ but the ITNs utilisation was not significant, $t_{(580)}=1.170, p>0.05$, with an effect size of 0.05 or $4.86 \%$ (Table 6). Faith clinics were not found in rural locations.

(5) Is there a relationship between acceptance and utilisation of RBM tools by these pregnant women?

As presented in Table 7, the utilisation of RBM tools which was found to be significantly related with the acceptance of RBM tools among pregnant women in the state government clinics $\left(r=0.398, N=582, p \leq 0.05 ; r^{2}=0.16\right)$ and pregnant women in faith clinics $\left(r=0.379, p \leq 0.05 ; r^{2}=\right.$ $0.14)$. This explained $16 \%$ and $14 \%$ of the variation between acceptance and utilisation among these women, respectively.
(6) What are the factors influencing (i) acceptance and (ii) utilisation of IPT and ITNs among pregnant women who access these health facilities in Oyo State?

The multiple regression model summary of the nine influencing variables (Table 8) significantly explained and predicted the acceptance of RBM tools among pregnant women in government clinics $\left(F_{(9,572)}=6.320, p \leq 0.05\right)$ but not in faith clinics. The variables accounted for $8 \%$ of variance in the pregnant women's acceptance of RBM tools whereas other variables not investigated accounted for the remaining $92 \%$. With respect to the $t$-test results in relation to the significant multiple regression coefficient obtained, the nine variables significantly predicted the acceptance of RBM tools through number of pregnancies $(t=5.172, \beta=0.217)$. Four other variables, educational qualification of the pregnant woman $(t=-2.871, \beta=-0.120)$, marital status $(t=$ $-2.928, \beta=-0.117)$, age of pregnant woman $(t=-2.805$; $\beta=-0.115)$, and husband's occupation $(t=-0.2212$, 
TABLE 4: Utilisation of ITNs and IPT by pregnant women in Oyo State.

\begin{tabular}{|c|c|c|c|c|c|c|c|}
\hline \multirow[b]{2}{*}{$\mathrm{S} / \mathrm{N}$} & \multirow[b]{2}{*}{ Statement } & \multicolumn{3}{|c|}{ Government clinics $(N=582)$} & \multicolumn{3}{|c|}{ Faith clinics $(N=50)$} \\
\hline & & $\begin{array}{l}\text { Yes } \\
\%\end{array}$ & $\begin{array}{l}\text { No } \\
\%\end{array}$ & $\begin{array}{c}\text { No } \\
\text { response } \\
\%\end{array}$ & $\begin{array}{l}\text { Yes } \\
\%\end{array}$ & $\begin{array}{c}\text { No } \\
\%\end{array}$ & $\begin{array}{c}\text { No } \\
\text { response } \\
\%\end{array}$ \\
\hline 1 & $\begin{array}{l}\text { I have been sleeping under an ITN before } \\
\text { this pregnancy. }\end{array}$ & $\begin{array}{c}366 \\
(62.9) \\
\end{array}$ & $\begin{array}{c}186 \\
(32.0) \\
\end{array}$ & $\begin{array}{c}30 \\
(5.2)\end{array}$ & $\begin{array}{c}11 \\
(22.0) \\
\end{array}$ & $\begin{array}{c}35 \\
(70.0) \\
\end{array}$ & $\begin{array}{c}4 \\
(8.0) \\
\end{array}$ \\
\hline 2 & $\begin{array}{l}\text { Sleeping under ITN is comfortable for } \\
\text { me. }\end{array}$ & $\begin{array}{c}426 \\
(73.2) \\
\end{array}$ & $\begin{array}{c}108 \\
(18.6)\end{array}$ & $\begin{array}{c}48 \\
(8.2) \\
\end{array}$ & $\begin{array}{c}24 \\
(48.0) \\
\end{array}$ & $\begin{array}{c}20 \\
(40.0) \\
\end{array}$ & $\begin{array}{c}6 \\
(12.0) \\
\end{array}$ \\
\hline 3 & I sleep under ITN daily in this pregnancy. & $\begin{array}{c}354 \\
(60.8) \\
\end{array}$ & $\begin{array}{c}194 \\
(33.3) \\
\end{array}$ & $\begin{array}{c}34 \\
(5.8) \\
\end{array}$ & $\begin{array}{c}11 \\
(22.0) \\
\end{array}$ & $\begin{array}{c}36 \\
(72.0) \\
\end{array}$ & $\begin{array}{c}3 \\
(6.0) \\
\end{array}$ \\
\hline 4 & I sleep under ITN all the time. & $\begin{array}{c}336 \\
(57.7) \\
\end{array}$ & $\begin{array}{c}211 \\
(36.3) \\
\end{array}$ & $\begin{array}{c}38 \\
(6.0) \\
\end{array}$ & $\begin{array}{c}9 \\
(18.0) \\
\end{array}$ & $\begin{array}{c}38 \\
(76.0) \\
\end{array}$ & $\begin{array}{c}3 \\
(6.0) \\
\end{array}$ \\
\hline 5 & I use an ITN because I find it easy to buy. & $\begin{array}{c}339 \\
(58.2) \\
\end{array}$ & $\begin{array}{c}195 \\
(33.5) \\
\end{array}$ & $\begin{array}{c}48 \\
(8.2) \\
\end{array}$ & $\begin{array}{c}30 \\
(60.0) \\
\end{array}$ & $\begin{array}{c}16 \\
(32.0) \\
\end{array}$ & $\begin{array}{c}4 \\
(8.0) \\
\end{array}$ \\
\hline 6 & $\begin{array}{l}\text { Two doses of anti-malarial drugs for IPT } \\
\text { were received during this pregnancy. }\end{array}$ & $\begin{array}{c}389 \\
(66.8) \\
\end{array}$ & $\begin{array}{c}180 \\
(30.9) \\
\end{array}$ & $\begin{array}{c}13 \\
(2.2) \\
\end{array}$ & $\begin{array}{c}19 \\
(38.0) \\
\end{array}$ & $\begin{array}{c}22 \\
(44.0) \\
\end{array}$ & $\begin{array}{c}9 \\
(18.0) \\
\end{array}$ \\
\hline 7 & $\begin{array}{l}\text { I will like to use IPT in my subsequent } \\
\text { pregnancies. }\end{array}$ & $\begin{array}{c}458 \\
(78.7)\end{array}$ & $\begin{array}{c}114 \\
(19.6)\end{array}$ & $\begin{array}{c}10 \\
(1.7)\end{array}$ & $\begin{array}{c}31 \\
(62.0)\end{array}$ & $\begin{array}{c}13 \\
(26.0)\end{array}$ & $\begin{array}{c}6 \\
(12.0)\end{array}$ \\
\hline
\end{tabular}

TABLE 5: Summary of $t$-test analysis on utilisation of IPT and ITNs by pregnant women in terms of health facility accessed (government and faith clinics).

\begin{tabular}{lcccccc}
\hline Facility accessed & $N$ & Mean & SD & df. & $t$ & $d$ \\
\hline IPT in government clinics & 582 & 3.42 & 0.80 & \multirow{2}{*}{630} & \multirow{2}{*}{5.81} & 0.23 \\
IPT in faith clinics & 50 & 2.70 & 1.20 & & \multirow{2}{*}{$0.000^{*}$} \\
\hline ITNs in government clinics & 582 & 7.79 & 2.56 & \multirow{2}{*}{630} & 0.99 & 0.16 \\
ITNs in faith clinics & 50 & 6.30 & 2.32 & & \\
\hline
\end{tabular}

${ }^{*}$ Significant at $p \leq 0.05$.

TABLE 6: Summary of $t$-test analysis on utilisation of IPT and ITNs by pregnant women in government clinics by location.

\begin{tabular}{lccccccc}
\hline Group & Location & $N$ & Mean & Std. Dev. & df. & $t$ & $d$ \\
\multirow{2}{*}{ IPT in government clinics } & Urban & 278 & 3.20 & 0.87 & \multirow{2}{*}{580} & -6.41 & 0.26 \\
& Rural & 304 & 3.61 & 0.67 & & & \multirow{2}{*}{$0.000^{*}$} \\
\hline \multirow{2}{*}{ ITNs in government clinics } & Urban & 278 & 7.98 & 2.07 & \multirow{2}{*}{580} & \multirow{2}{*}{1.17} & 0.05 \\
& Rural & 304 & 7.62 & 2.92 & & $0.089^{\text {NS }}$ \\
\hline
\end{tabular}

${ }^{*}$ Significant at $p \leq 0.05, \mathrm{NS}=$ not significant at $p>0.05$.

TABLE 7: Correlation matrix of relationship between acceptance and utilisation of RBM tools among pregnant women in Oyo State.

\begin{tabular}{|c|c|c|c|c|c|}
\hline \multicolumn{4}{|c|}{ Government clinics } & \multicolumn{2}{|c|}{ Faith clinics } \\
\hline & & Acceptance & Utilisation & Acceptance & Utilisation \\
\hline \multirow{3}{*}{ Acceptance } & Pearson Correlation & 1 & $0.398^{* *}$ & 1 & $0 . .379^{* *}$ \\
\hline & Sig. (2-tailed) & & 0.000 & & 0.007 \\
\hline & $N$ & 582 & 582 & 50 & 50 \\
\hline \multirow{3}{*}{ Utilisation } & Pearson Correlation & $.398^{* *}$ & 1 & $0.379^{* *}$ & 1 \\
\hline & Sig. (2-tailed) & 0.000 & & 0.000 & \\
\hline & $N$ & 582 & 582 & 50 & 50 \\
\hline
\end{tabular}

${ }^{* *} p \leq 0.01$.

$\beta=-0.093$ ), also contributed significantly but inversely to the acceptance of RBM tools (Table 8).

The multiple regression of the nine influencing independent variables of the utilisation significantly explained and predicted the utilisation of RBM tools among pregnant women in government clinics $\left(F_{(9,572)}=3.607, p \leq 0.05\right)$ but not in faith clinics (Table 9).

The nine variables accounted for 3.9\% variance in the utilisation of RBM tool whereas other variables not investigated accounted for the remaining 96.1\%. Concerning the 
TABLE 8: Factors influencing acceptance of RBM tools among pregnant women in government and faith clinics.

\begin{tabular}{|c|c|c|c|c|c|}
\hline Dependent variable & $R^{2}$ & $F$ & Factors influencing acceptance & $\beta$ & $t$ \\
\hline \multirow{9}{*}{$\begin{array}{l}\text { Acceptance of RBM tools among } \\
\text { pregnant women in government clinics }\end{array}$} & \multirow{9}{*}{0.301} & \multirow{9}{*}{$6.32^{*}$} & Age of pregnant woman & -0.115 & $-2.805^{*}$ \\
\hline & & & Educational qualification of the pregnant woman & -0.120 & $-2.805^{*}$ \\
\hline & & & Number of pregnancies had & 0.217 & $5.172^{*}$ \\
\hline & & & Loss of pregnancy & 0.036 & 0.598 \\
\hline & & & Cause of miscarriage & -0.068 & -1.111 \\
\hline & & & Occupation of pregnant woman & 0.062 & 1.485 \\
\hline & & & Marital status & -0.117 & $-2.928^{*}$ \\
\hline & & & Religion & 0.007 & 0.169 \\
\hline & & & Husband's occupation & -0.093 & $-2.212^{*}$ \\
\hline
\end{tabular}

Acceptance of RBM tools among

$0.5210 .66^{\mathrm{NS}}$

pregnant women in faith clinics

${ }^{*}$ Significant at $p \leq 0.05, \mathrm{NS}=$ not significant at $p>0.05$.

TABLE 9: Factors influencing utilisation of RBM tools among pregnant women in government and faith clinics in Oyo State.

\begin{tabular}{|c|c|c|c|c|c|}
\hline Dependent variable & $R^{2}$ & $F$ & Factors influencing utilisation & $\beta$ & $t$ \\
\hline \multirow{9}{*}{$\begin{array}{l}\text { Utilisation of RBM tools among } \\
\text { pregnant women in government clinics }\end{array}$} & \multirow{9}{*}{0.232} & \multirow{9}{*}{$3.607^{*}$} & Husband's occupation & -0.071 & -1.644 \\
\hline & & & Marital status & -0.132 & $-3.248^{*}$ \\
\hline & & & Age of pregnant woman & -0.070 & -1.686 \\
\hline & & & Educational qualification & -0.106 & $-2.496^{*}$ \\
\hline & & & Number of pregnancies had & 0.121 & $2.818^{*}$ \\
\hline & & & Loss of pregnancy & -0.038 & -0.608 \\
\hline & & & Causes of miscarriage & -0.003 & -0.054 \\
\hline & & & Husband's occupation & -0.071 & -1.644 \\
\hline & & & Religion & 0.033 & 0.791 \\
\hline
\end{tabular}

Utilisation of RBM tools among

pregnant women in faith clinics

$0.392 \quad 0.807^{\mathrm{NS}}$

* Significant at $p \leq 0.05$, NS $=$ not significant at $p>0.05$.

$t$-test results in relation to the significant effect of the multiple regression coefficient obtained, the nine variables significantly predicted the utilisation of RBM tools by pregnant women in government clinics through the number of pregnancies had $(t=2.818, \beta=0.121)$. Marital status and educational qualification of the pregnant women also contributed significantly but inversely to the utilisation of RBM tools among these women $(t=-3.248, \beta=-0.132$ and $t=-2.496, \beta=-0.106$, resp.).

\section{Discussion}

5.1. Acceptance and Utilisation of RBM Tools in Pregnancy. The findings with respect to the acceptance of RBM tools (IPT and ITNs) by pregnant women indicated that pregnant women who accessed government clinics accepted these RBM tools better than those who accessed faith clinics. Between $50 \%$ and $72 \%$ of the pregnant women who accessed government clinics accepted IPT and ITNs whereas between $30 \%$ and $72 \%$ of pregnant women who accessed faith clinics accepted these RBM tools. The overall acceptance by these women (even when pregnant women who accessed faith clinics claimed they engage in dual registration) could be as a result of adequate enlightenment on the knowledge of RBM programme provided to the pregnant women in government clinics through health education at ANC visits, which is a regular practice of primary healthcare in the clinics. This must have contributed to the favourable acceptance of the RBM tools. The targets of over $82 \%$ in the use of RBM tools by pregnant women were set by the African Heads of State to be achieved by year 2010. The observed trend in this study is an indication that these targets are yet to be fully achieved. The level of education of an individual generally dichotomises one into an ignorant or informed person. According to [16], health education helps people understand health and how their behaviour may affect their health. Since such education encourages people to make their own choices for a healthy life, it will ensure the success of the prevention, treatment, and control of malaria programme put in place in order to reduce to the barest minimum maternal and child morbidity and mortality, in the state.

Other findings in this study indicate that health facility accessed by the pregnant women significantly influenced acceptance: government clinics: $t_{(630)}=3.51, p \leq 0.05$; faith clinics: $t_{(630)}=4.15, p \leq 0.05$. Acceptance was also location based as women in the rural locations significantly accepted 
IPT in pregnancy compared to those in urban locations $(t=$ $4.12, p \leq 0.05$ ) but location did not significantly influence the acceptance of ITNs for this group of women. This implied that RBM programme in Oyo State is a healthcare focused programme geared towards the rural people through the primary healthcare. This way, the study findings corroborated [17]. Thus, the rural dwellers see RBM programme as their own programme which they embrace wholeheartedly more than the urban dwellers. Personal experiences of the researchers show that dwellers in the urban areas take malaria for granted and probably see it as a common disease occurrence.

Findings indicate a modest level of the utilisation of IPT and ITNs by the pregnant women. More of the pregnant women in government clinics (between 58\% and 73\%) utilised IPT and $67.2 \%$ used ITNs whereas between $18 \%$ and $60 \%$ and $38.0 \%$ of those who accessed faith clinics used these tools, respectively. This was significant at $p \leq 0.05$, respectively. These figures are slightly better than the 2005 targets. The observed difference could be attributed to the religious beliefs and practices of the women in faith clinics who do not believe in the use of drugs even though they engage in dual registration. The study of [13] finds support in respect of this finding. Although researchers like [17] revealed that factors such as availability of nets, cost of nets, and inadequate information on where to obtain the nets and the attitude of users towards the use of net had great influence on the poor and improper utilisation of nets (ITNs), the findings of this present study seem to have indicated a considerable improvement in the utilisation of ITNs among the pregnant women. Findings differed markedly from the findings of [18] that reported less than $10 \%$ usage of nets among pregnant women and children in Uganda but are in consonance with the [19] study which reported 58\% usage of ITNs among women attending ANC and delivery units in Burkina Faso and [20] that reported a variation between $32 \%$ and $69 \%$ usage of ITNs among pregnant women in six African countries, Nigeria inclusive. Findings equally find support in the study of [21] which found that ITNs use in Niger improved after a nationwide integrated campaign.

The influence of location on the utilisation of RBM tools by the pregnant women in this study was important as pregnant women in rural locations who accessed government clinics utilised IPT compared to those in urban areas, significant at $p \leq 0.05$. In this regard, findings in Nigeria $[22,23]$ which corroborated [14] are in support of the fact that the use of nets was very variable among urban and rural communities in Oyo and Ekiti States, respectively. A national malaria situation survey conducted in 2000 reported by [4] also indicated that net use among pregnant women in Nigeria seems to be generally low in all the six geopolitical zones. It also indicated a generally poor usage of nets among all categories of people in Nigeria with only $20 \%$ of households owning nets, some of which are not necessarily ITNs, whereas [14] observed a higher coverage of the usage of nets in urban areas. There is therefore need to further reach pregnant women in urban locations to improve their attitude to IPT and ITNs utilisation as well as those who access faith clinics.

In addition, a positive but low correlation seems to exist between acceptance and utilisation of IPT and ITNs among pregnant women who accessed government clinics $(r=$ 0.398 ) accounting for $16 \%$ variance in utilisation compared to those who accessed faith clinics $(r=0.379)$ accounting for $14 \%$ variance in utilisation. This implied that, all things being equal, high acceptance implies reliable utilisation of IPT and other RBM programme packages. The acceptability of and receptiveness to RBM tools by some of the pregnant women could have facilitated their utilisation of the tools with ease. The implication of this finding is that any effective public enlightenment and sensitisation carried out on RBM programme and tools will make the right impact on reducing the menace of malaria on pregnant women irrespective of the health facility accessed.

\subsection{Factors Influencing Acceptance and Utilisation of Roll} Back Malaria Tools. From the findings in this study, pregnant women in the state have a high acceptance of RBM tools. It appears, however, that the acceptance of these tools by pregnant women who accessed government clinics depended on factors such as number of pregnancies had $(\beta=0.217)$ which significantly and positively influenced these women's acceptance of these tools, but educational qualification of the pregnant woman $(\beta=-0.120)$, marital status $(\beta=-0.117)$, age of the pregnant women $(\beta=-0.115)$, and husband's occupation $(\beta=-0.093)$, though significant, inversely influenced acceptance. Other factors were not significant. What these findings imply is that as the age increased or educational qualification and marital status or husbands' occupations of these women improved, their acceptance of RBM tools became low. On the issue of the utilisation of the tools by pregnant women who accessed government clinics, the findings revealed that utilisation was influenced by such factors as the number of pregnancies had $(\beta=0.121)$ which contributed significantly and positively to utilisation and marital status $(\beta=-0.132)$ and educational qualification of the pregnant women $(\beta=-0.106)$ which contributed significantly and inversely to the utilisation of RBM tools among these women. These variables did not influence both the acceptance and utilisation of pregnant women in faith clinics.

Three Variables. Number of pregnancies, educational qualification of the pregnant women, and marital status which were observed to significantly and consistently influence the acceptance and utilisation of RBM tools in this study seem to be contiguously related to one another and portend strong indications that the observed finding about these women has grave implications for their purchasing powers. Precisely, decisions about spending money are predominantly and traditionally made by men in many African cultures [24]. Also, a large number of the pregnant women who participated in the study were housewives who were with no adequate means of livelihood of their own and who had to depend on their husbands' incomes to be able to purchase the nets and the drugs. Some of the women may, therefore, not be able to make independent financial decisions since they do not have much income of their own and as such, their acceptance and utilisation of these tools could have been influenced not only by the number of pregnancies had, but also by marital status and husbands' occupations. Thus, the spouse and the nature 
of occupation are central to the women's responses to these tools. Findings also corroborate Pulford, Herzel, Bryant, Siba, and Mueller in [13] who reported that lack of affordability is an important barrier to ownership of ITNs. With this kind of findings, the attainment of the two main objectives of RBM programme which are "reducing the burden of malaria particularly in the two most vulnerable groups" (pregnant women and children under 5 years of age) and "contributing to the positive health and socio-economic development of the nation" is feasible and possible, all things being equal. Among the pregnant women who accessed faith clinics, the findings indicated that all the nine variables did not predict their acceptance and utilisation of the RBM tools primarily because these women are not necessarily inclined to accept or utilise these tools due to their religious beliefs and practices.

\section{Conclusion}

The study established the current status of the acceptance and utilisation of RBM programme tools (ITNs and SP in pregnancy) among pregnant women who accessed two models of healthcare facilities in Oyo State from 2001 to 2009, an initiative implemented with the purpose of stemming of malaria-related morbidity and mortality among these pregnant women and their unborn children. Though the acceptance and utilisation of RBM tools were higher among pregnant women who accessed government PHC clinics and in rural areas than among pregnant women who accessed faith clinics and in urban areas, these were far from meeting the set targets. Pregnant women's marital status and husbands' occupations significantly and statistically influenced acceptance while husbands' occupations influenced the utilisation of RBM tools implying that spouses' statuses play significant roles in achieving set targets.

We recommend that intensive effort should be made by healthcare providers to encourage especially more of the educated urban women to utilise RBM programme tools, especially the ITNs. RBM programme should not focus only on the utilisation of RBM tools but the scope should be expanded to include information dissemination on behavioural change towards malaria and its consequences. Malaria consumables such as Insecticide-Treated Nets (ITNs) and medications such as Sulphadoxine-Pyrimethamine should be made available at the various health centres and given freely. They should also be available at the open chemist stores at cheap and affordable prices to the average person.

\section{Abbreviations Used in the Paper}

RBM: Roll Back Malaria

TBAs: Traditional Birth Attendants

ACTs: Artemisinin-Based Combination Therapies

IPT: Intermittent Preventive Treatment in pregnancy

ITNs: Insecticide-Treated Nets

LLINs: Long-Lasting Insecticides Nets

PHC: Primary Healthcare Centre
U-5: Children under five years of age

LGA: Local government area

NMCP: National Malaria Control Programme

FMOH: $\quad$ Federal Ministry of Health of Nigeria

FANC: $\quad$ Focused Antenatal Care

STDs: $\quad$ Sexually Transmitted Diseases

HIV/AIDS: Human Immune Virus/Acquired Immune Deficiency Syndrome

TB: Tuberculosis

WHO: World Health Organization.

\section{Ethical Approval}

Ethical approval was obtained from Oyo State Ethical Review Committee and the Local Government Commission and heads of the LGA healthcare facilities prior to the commencement of the study.

\section{Consent}

At each health centre and faith clinic or mission home used, consent for participation was sought and the participants willingly and voluntarily gave their consent.

\section{Conflict of Interests}

The authors declare that they do not have any conflict of interests in relation to the publication of this paper.

\section{Acknowledgments}

The authors acknowledge all healthcare providers and participants whose willingness and participation in the study made it a success. They thank Dr. Mayowa Owolabi, Neurology Department, UCH, Ibadan, Nigeria, for accepting to undertake an initial peer review of the paper.

\section{References}

[1] L. Salako, "Salako canvasses final battle against malaria," The Punch Newspaper, p. 46, 2005.

[2] WHO, "Roll Back Malaria: 'increasing the momentum," WHO, 1999, http://www.rbm.who.int/.

[3] C. A. Miguel, V. L. Tallo, L. Manderson, and M. A. Lansang, "Local knowledge and treatment of malaria in Agusan del Sur, the Philippines," Social Science \& Medicine, vol. 48, no. 5, pp. 607-618, 1999.

[4] Federal Ministry of Health, Malaria Control in Nigeria: A Strategy for Behaviour Change Communication 2004-2005, Roll Back Malaria Control Program, Department of Public Health, Federal Ministry of Health Nigeria, Abuja, Nigeria, 2004.

[5] Health Reform Foundation of Nigeria (HERFON), Nigeria Health Review, Health Reform Foundation of Nigeria (HERFON), 2006.

[6] O. Onwujekwe, K. Hanson, and J. Fox-Rushby, "Inequalities in purchase of mosquito nets and willingness to pay for insecticide-treated nets in Nigeria: challenges for malaria control intervention," Malaria Journal, vol. 3, article 6, 2004. 
[7] Roll Back Malaria, The Africa Malaria Report: The Burden of Malaria in Africa, Roll Back Malaria, 2003, http://www.againstmalaria.com/downloads/RBMBurdenMalariaAfrica.pdf.

[8] O. A. Moronkola, F. A. Okanlawon, and O. C. Adewale, "Prevlence of, knowledge of nature and health seeking behavior during malaria attack in Agbowo community, Ibadan, Nigeria," West African Journal of Nursing, vol. 17, p. 2, 2006.

[9] World Health Organization, Strategic Framework for Malaria Control in Pregnancy in WHO African Region, World Health Organization, Geneva, Switzerland, 2004, http://www.afro.who .int/index.php?option=com_docman\&task=doc_download\&gid $=147$.

[10] World Health Organization, WHO Expert Committee on Malaria, Twentieth Report, WHO Technical Report Series no. 892, World Health Organization, Geneva, Switzerland, 2000, http://whqlibdoc.who.int/trs/WHO_TRS_892.pdf.

[11] Roll Back Malaria, Scaling-Up Insecticide-Treated Netting Programmes in Africa: A Strategic Framework for Coordinated National Action, Roll Back Malaria, Geneva, Switzerland, 2002, http://www.rollbackmalaria.org/files/files/partnership/wg/wgitn/docs/WINITN_StrategicFramework.pdf.

[12] Federal Ministry of Health and National Malaria Control Programme, Strategic Plan 2009-2013, A Road Map for Malaria Control in Nigeria, National Malaria Control Programme, Abuja, Nigeria, 2009-2013.

[13] E. E. Ambrose, H. D. Mazigo, J. Heukelbach, O. Gabone, and D. L. Nwizamholya, "Knowledge, attitudes and practices regarding malaria and mosquito net use among women seeking antenatal care in Iringa, South-Western Tanzania," Tanzania Journal of Health Research, vol. 13, no. 3, pp. 188-195, 2011, http://www.popline.org/node/536192.

[14] P. Guillet, "Insecticide-treated nets in Africa: where do we stand'? Parasitic disease and vector control," Africa Health (Incorporating Medicine Digest), vol. 23, no. 6, pp. 20-23, 2001.

[15] Department of Planning and Oyo State Ministry of Health, Oyo State Prevalence of Malaria Data, Oyo State Comprehensive Health Bulletin, 2007.

[16] F. O. Awotunde, Roll Back Malaria: Acceptance and Utilisation of Insecticides Treated Bed Nets among Pregnant Women and Children between Ages 0-5 Years in Ila Local Government Area of Osun State, PHC TC, University College Hospital, Ibadan, Nigeria, 2006.

[17] T. Oguonu, H. U. Okafor, and H. A. Obu, "Caregivers's knowledge, attitude and practice on childhood malaria and treatment in urban and rural communities in Enugu, South-East Nigeria," Public Health, vol. 119, no. 5, pp. 409-414, 2005.

[18] F. Mugisha and J. Arinaitwe, "Sleeping arrangements and mosquito net use among under-fives: results from the Uganda Demographic and Health Survey," Malaria Journal, vol. 2, article 40, 2003.

[19] S. B. Sirima, A. H. Cotte, and A. Konate, "Malaria prevention during pregnancy: assessing the disease burden one year after implementing a program of intermittent strategies in Koupela district, Burkina Faso," The American Journal of Tropical Medicine and Hygiene, vol. 77, pp. 205-211, 2006.

[20] C. A. Baume and M. C. Marin, "Intra-household mosquito net use in Ethiopia, Ghana, Mali, Nigeria, Senegal, and Zambia: are nets being used? Who in the household uses them?" American Journal of Tropical Medicine and Hygiene, vol. 77, no. 5, pp. 963971, 2007.

[21] J. Thwing, N. Hochberg, J. V. Eng et al., "Insecticide-treated net ownership and usage in Niger after a nationwide integrated campaign," Tropical Medicine \& International Health, vol. 13, no. 6, pp. 827-834, 2008.

[22] K. J. Okop, Readiness to prevent malaria with insecticides treated nets in rural and urban areas of Ekiti State [MPH Thesis], Faculty of Public Health, College of Medicine, University of Ibadan, Ibadan, Nigeria, 2004.

[23] Y. O. Awobiyi, Factors influencing intention to use insecticide treated bed nets among rural and urban communities in Ibadan, Oyo State, Nigeria [MPH Thesis], Faculty of Public Health, College of Medicine, University of Ibadan, Ibadan, Nigeria, 2004.

[24] J. Sumukwo, M. Kiptui, and G. J. Cheserek, "Economic valuation of improved solid waste management in Eldoret Municipality," Journal of Emerging Trends in Economics \& Management Sciences, vol. 3, no. 6, pp. 962-970, 2012. 


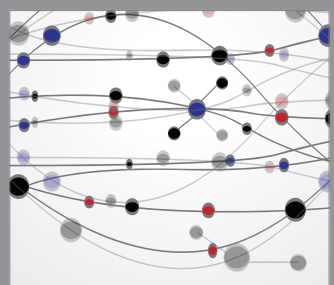

The Scientific World Journal
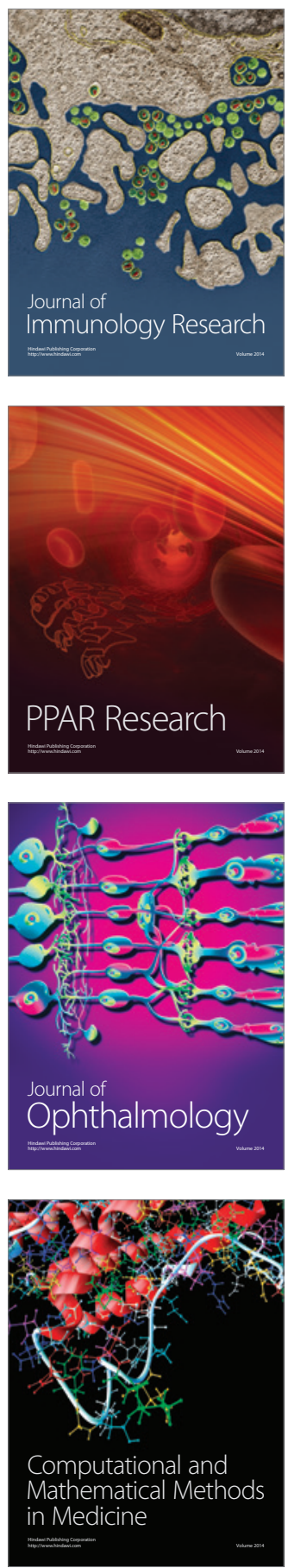

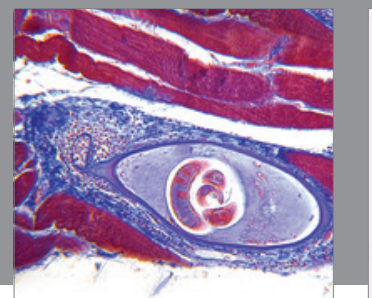

Gastroenterology

Research and Practice
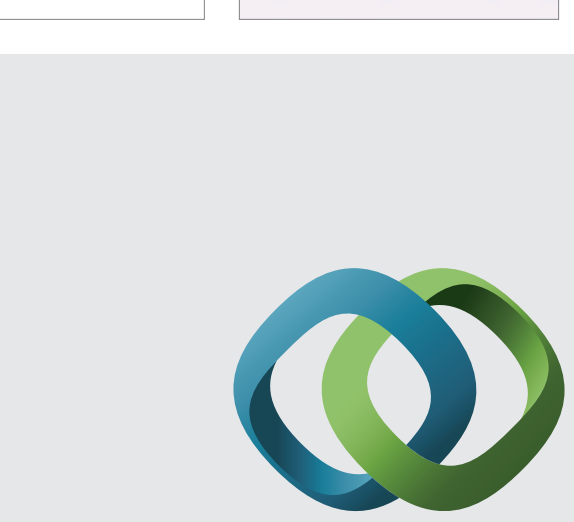

\section{Hindawi}

Submit your manuscripts at

http://www.hindawi.com
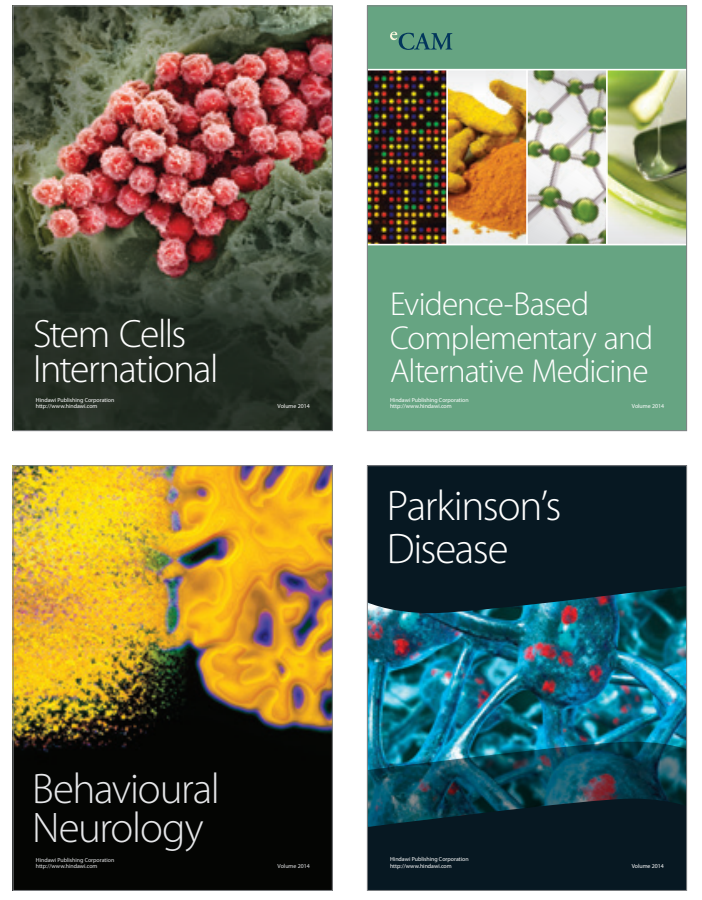
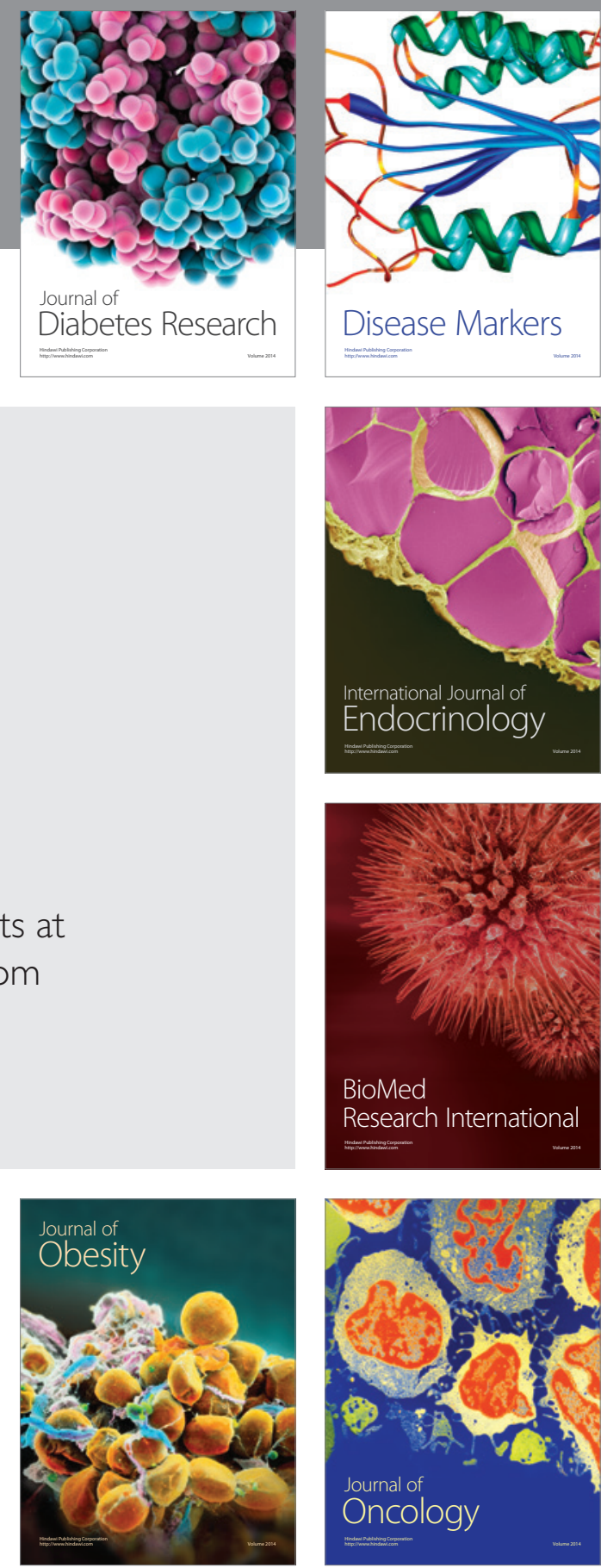

Disease Markers
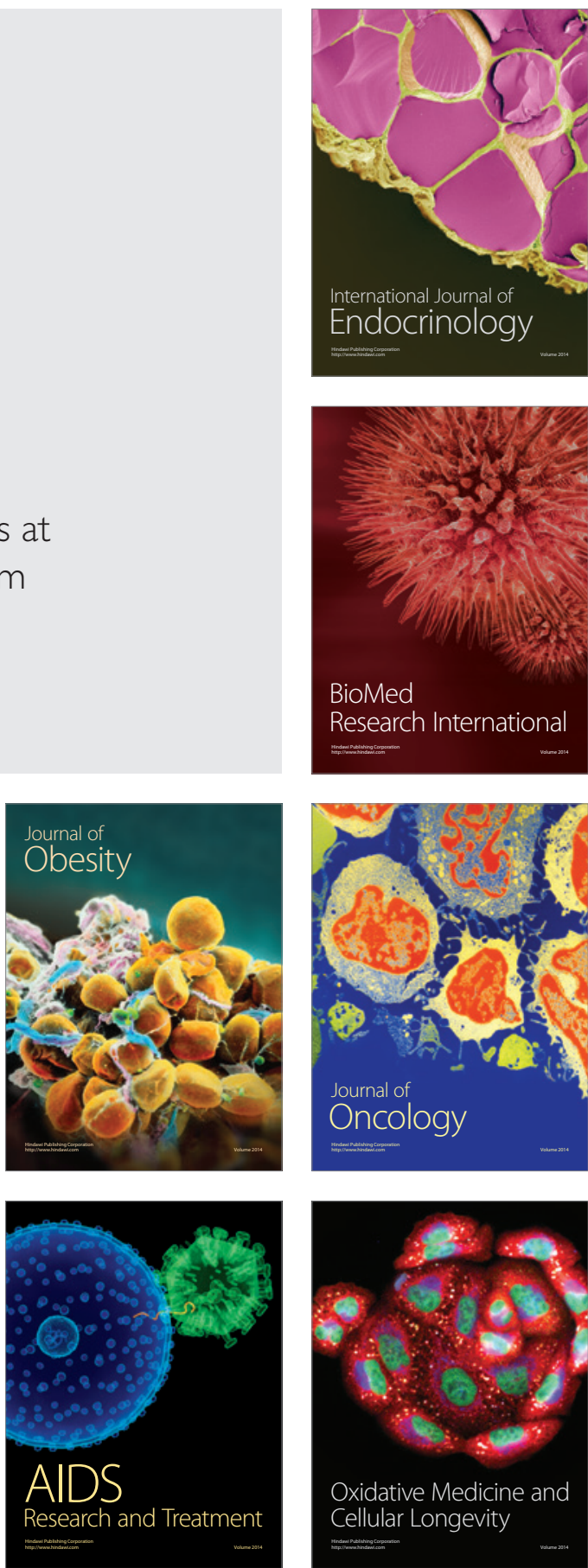